\title{
Drought Stress Induces Differential DNA Methylation Shift at Symmetric and Asymmetric Cytosine Sites in the Promoter Region of ZmEXPB2 Gene in Maize
}

\author{
Zainab Rehman ${ }^{1}$, Ayesha Baig ${ }^{1}$, Ghulam Shabir ${ }^{2}$, Kashif Aslam², Muhammad Shahzad ${ }^{3}$, Sidra Rehman ${ }^{4}$, Shahid \\ Masood Shah ${ }^{1}$ and Abdul Rehman Khan ${ }^{*}$ \\ ${ }^{1}$ Department of Biotechnology, COMSATS University Islamabad, Abbottabad Campus, Pakistan \\ ${ }^{2}$ Institute of Molecular Biology and Biotechnology, Bahauddin Zakariya University Multan, Pakistan \\ ${ }^{3}$ Department of Agronomy, University College of Agriculture and Environmental Sciences, Islamia University Bahawalpur, \\ Pakistan \\ ${ }^{4}$ Laboratory of Functional Genomics, Department of Biosciences, COMSATS University Islamabad, Pakistan \\ *For Correspondence: arehman@cuiatd.edu.pk; abdulrehmankhan84@gmail.com \\ Received 28 August 2020; Accepted 24 October 2020; Published 10 January 2021
}

\begin{abstract}
$\beta$-expansin 2 (EXPB2) gene induces drought tolerance in different plant species including maize. Different epigenetic mechanisms like DNA methylation, histone modification and RNA interference affect the gene activities under stress conditions. DNA methylation, an important epigenetic mechanism, could be involved in the regulation of ZmEXPB2 gene under drought stress in maize. Plants of drought sensitive variety 'Jalal' were grown till $4^{\text {th }}$ leaf stage under well-watered conditions. At $5^{\text {th }}$ leaf stage, plants were divided in two groups i.e., well-watered (100\% water holding capacity) or drought stress ( $0 \%$ water holding capacity for 15 days). Plants subjected to drought stress showed clear signs of stress by significant decrease in fresh weight of whole plant, $6^{\text {th }}$ leaf length, stunted secondary root growth and increased primary root length. DNA methylation profile of three regions (denoted as $-1.7 \mathrm{k},-1.3 \mathrm{k}$ and $-0.8 \mathrm{k}$ ) in the promoter of ZmEXPB2 gene, of root DNA, were evaluated. Under well-watered conditions, heterogeneity in DNA methylation profile along the promoter sequence was observed. Regions $-1.7 \mathrm{k}$ and $-1.3 \mathrm{k}$ were methylated whereas the region $-0.8 \mathrm{k}$ was nonmethylated. After the comparison of DNA methylation profile of well-watered and drought stress plants, no change in $-1.7 \mathrm{k}$ and $-0.8 \mathrm{k}$ regions was observed. However, the $-1.3 \mathrm{k}$ region had significant decrease in the DNA methylation at symmetric cytosine sites i.e., cytosine-guanine (CG) dinucleotides and cytosine-adenine/cytosine/thymine-guanine ( $\mathrm{CHG}$ where $\mathrm{H}=\mathrm{A}, \mathrm{C}$ or $\mathrm{T}$ ) trinucleotide and significant increase at asymmetric cytosine sites $(\mathrm{CHH})$ under the stress condition. In addition, significant increase in the gene expression of $\mathrm{ZmEXPB2}$ under drought was also observed. In conclusion, drought stress conditions induce DNA hypomethylation at CG, and $\mathrm{CHG}$ sites and DNA hypermethylation at $\mathrm{CHH}$ sites in the middle region of the promoter of ZmEXPB2 gene. This shift can be associated with the up regulation of ZmEXPB2 gene which in turn increased primary root length as a plant stress response mechanism. (C) 2021 Friends Science Publishers
\end{abstract}

Keywords: Epigenetics; Hypermethylation; Hypomethylation; Water deficit conditions; Zea mays L.; ZmEXPB2

\section{Introduction}

Plants, being sessile in nature, constantly encounter environmental changes and have developed multiple adaptive responses through regulation of different physiological and developmental mechanisms. This modulation is achieved through the regulation of activities of stress responsive genes (Farooq et al. 2011; Wang et al. 2011). In recent decades, evidences have confirmed the role of different epigenetic mechanisms, like DNA methylation, histone modification and RNA interferences, in the regulation of gene expression under stress conditions
(González et al. 2013; Li et al. 2014; Kaleem et al. 2019). DNA methylation is addition of methyl group to either adenine or cytosine. In eukaryotes, it mainly occurs at cytosine to make it 5-methylcytosine $(5-\mathrm{mC})$. The 5methylcytosines are studied under three contexts: $\mathrm{CG}, \mathrm{CHG}$ and $\mathrm{CHH}$ ( $\mathrm{H}$ corresponds to $\mathrm{A}, \mathrm{C}$ or $\mathrm{T}$ ) (Zilberman et al. 2007; Lang et al. 2015). DNA methylation is evolutionarily ancient and play significant role in various important biological processes of plant growth and development like seed development, hybrid vigor, metabolite synthesis (Xing et al. 2015), heterosis of hybrids (Kawanabe et al. 2016; Lauss et al. 2018), fruit ripening (Zhong et al. 2013; Liu et

To cite this paper: Rehman Z, A Baig, G Shabir, K Aslam, M Shahzad, S Rehman, SM Shah, AR Khan (2021). Drought stress induces differential DNA methylation shift at symmetric and asymmetric cytosine sites in the promoter region of ZmEXPB2 Gene in maize. Intl J Agric Biol 25:319-326 
al. 2015; Li et al. 2018), synthesis of secondary metabolites (Conde et al. 2017), genome stability and gene regulation (Bird 2002). Involvement of DNA methylation in regulating stress responsive genes under abiotic stress especially in drought has been reported in many studies (González et al. 2011, 2013).

Drought is one of the most important abiotic stresses that significantly effects the plant growth and yield of crops, including maize (Zea mays L.), posing a serious threat to achieving the goal of food security (Hussain et al. 2018; Mi et al. 2018; Shafiq et al. 2019). It affects the morphological trails, photosynthesis rate and grain quality in terms of nutritional composition and quantity in terms of yield of maize (Gheysari et al. 2017; Hussain et al. 2019; Danish et al. 2020). Therefore, a better understanding of the plant response mechanisms against drought stress is vital.

Plant responds to drought stress by inducing changes in plant physiology through regulation in expression of many underlying drought responsive genes (Farooq et al. 2014, 2017). One important physiological process is cell wall elongation which influences the plant growth by regulating the cell extension and is often considered to be the earliest visible effect of stress (Gall et al. 2015; Ezquer et al. 2020). It is regulated by proteins like endo- 1,4-b-Dendoglucanase (EGase), xyloglucan endotransglucosylase (XET), expansins (EXP), and plasma membrane proton pump (PM-H+-ATPase, MHA) (Geilfus et al. 2011; Kaleem et al. 2019). Various studies have confirmed the importance of expansins in the cell wall elongation and plant response against abiotic stress (Guo et al. 2011; Zhou et al. 2015; Marowa et al. 2016). Among expansins, $\beta$ expansin is a large gene family, present in maize and other plants, the protein products of which play multiple roles but are mainly involved in cell enlargement through cell wall loosening by disturbing the hydrogen bonding within cell wall's cellulose fibers relying on $\mathrm{pH}$ as $\mathrm{H}^{+}$-ATPase inhibition causes increase in cell wall $\mathrm{pH}$ (Zhao et al. 2012) thus contributing to growth of plant tissue (Boron et al. 2015). An upregulation in the expression of different expansin genes like TaEXPB23 in Nicotiana tabacum and RhEXPA4 gene in Arabidopsis under drought condition have been observed (Li et al. 2011; Lü et al. 2013). EXPB2, an important gene of $\beta$-expansin gene family, show upregulation under different abiotic stresses like salinity and drought stress in different species including maize (Guo et al. 2011; Zhao et al. 2012; Li et al. 2014; Kaleem et al. 2019). In Glycine max, the higher expression of EXPB2 gene accompanied with improved root tolerance to water stress was reported in water stressed plants (Guo et al. 2011). The upregulation of EXPB2 gene in Solanum pennellii under drought stress conditions indicated towards the strong association between EXPB2 gene and drought stress tolerance (Egea et al. 2018). Interestingly, the involvement of epigenetic mechanisms at both DNA methylation and histone acetylation levels in the regulation of $E X P B 2$ gene in maize against salt stress have already been reported (Li et al. 2014; Kaleem et al. 2019). Li et al. (2014) revealed an increase in $\mathrm{H} 3 \mathrm{~K} 9$ acetylation was associated with the ZmEXPB2 up-regulation under salt stress conditions. Similarly, ZmEXPB2 gene up-regulation by the DNA hypomethylation in this gene induced by salt stress in maize has been reported (Kaleem et al. 2019). But the ZmEXPB2 gene regulation by DNA methylation shift in maize under drought stress need to be explore. Therefore, to test the hypothesis that DNA methylation is involved in the regulation of $Z m E X P B 2$ gene under drought stress, this study was designed. Single base pair resolution of three regions in the promoter of $Z m E X P B 2$ gene through bisulfite (direct) sequencing revealed the induction of region-specific differential DNA methylation shift at symmetric and asymmetric cytosine sites in promoter of ZmEXPB2 gene due to drought stress.

\section{Materials and Methods}

\section{Plant material development and drought treatment}

Seeds of a drought sensitive maize (Zea mays L.) variety "Jalal" (Basir et al. 2018) were acquired from Cereal Crops Research Institute (CCRI), Pirsabak, Nowshera, Pakistan. Seeds imbibition was done by soaking in distil water for an interval of four hours at a temperature of $45^{\circ} \mathrm{C}$. Six pots (19.5 cm in diameter and $25 \mathrm{~cm}$ in height each) having $2 \mathrm{~kg}$ of silty loam soil (50\% silt, $30 \%$ clay and $20 \%$ sand) were prepared and three imbibed seeds were then sown per pot. After germination, the seedlings were thinned to one seedling per pot. The plants were grown in $13 \mathrm{~h}$ daylight at a temperature around $28 / 22^{\circ} \mathrm{C}$ (day/night) in open air nursery. As water holding capacity can be determined by measuring soil moisture at filed capacity and at permanent welting point, the amount of water needed to achieve $100 \%$ water holding capacity (WHC) of the soil was measured by gravimetric method using the following formula:

$$
\text { Soil moisture content }=\frac{(\text { Fresh weight }- \text { Dry weight })}{\text { Dry weight }}
$$

The plants were irrigated to $100 \%$ WHC till $5^{\text {th }}$ leaf stage by adding $460 \mathrm{~mL}$ water per pot per day (Virlouvet et al. 2011). Each pot was provided with $15 \mathrm{~g}$ of NPK at $3^{\text {rd }}$ leaf stage. At $5^{\text {th }}$ leaf stage, drought-stress was carried out in three selected pots by withholding the irrigation and maintaining the $0 \% \mathrm{WHC}$ for 15 days and the remaining plants were well-watered (100\% WHC). The experimental design was Completely Randomize Design (CRD) consisted of 3 replicates. The whole plants along with roots were harvested. Phenotypic data from three plants per treatment was recorded for fresh plant weight, $6^{\text {th }}$ leaf length and primary root length. Roots from each plant was separately sampled and stored at $-80^{\circ} \mathrm{C}$ for molecular analysis. Two plants from each treatment were used for the molecular analysis. 


\section{DNA and RNA extraction}

DNA from $200 \mathrm{mg}$ root sample of each plant was separately extracted by using DNA extraction kit. RNA from $200 \mathrm{mg}$ root sample from each plant was extracted through CTAB method with slight modifications (Murray and Thompson 1980). The quality of the extracted DNA and RNA was checked by running on $1 \%$ agarose gel. The quantification of DNA and RNA was done by determining the visible light-UV absorbance on the Colibri NanoDrop spectrometer (Titertek Berthold, Germany).

\section{Bisulfite treatment and direct sequencing of the amplified PCR product}

EZ DNA Methylation-Gold" kit (Zymo Research) was used to treat $350 \mathrm{ng}$ of genomic DNA, from each extracted sample, with sodium bisulfite by following manufacturer's protocol. $2 \mu \mathrm{L}$ of eluded solution was used for each PCR reaction. To analyze the overall methylation pattern of the promoter region of ZmEXPB2, bisulfite specific PCR primer pairs were designed to amplify three regions (denoted as $-1.7 \mathrm{k},-1.3 \mathrm{k}$ and $-0.8 \mathrm{k}$ ) located in the promoter of ZmEXPB2 gene (Table 1) through Methyl Primer Express v. 1.0 software (Applied Biosystems). For this purpose, $1800 \mathrm{bp}$ sequence, upstream of Transcription Start Site (TSS) was used.

The PCR was carried out using $2 \mathrm{X}$ Topsimple DyeMIX®_multi HOT master mix with following reagent quantitates: $15 \mu \mathrm{L}$ of final volume containing $7.5 \mu \mathrm{L}$ of master mix, $1.5 \mu \mathrm{L}$ of forward and reverse primer each, 2 $\mu \mathrm{L}$ of DNA template (bisulfite treated) and $2.5 \mu \mathrm{L}$ of $\mathrm{dH}_{2} \mathrm{O}$. The PCR program used was as follow: an initial denaturation step $\left(95^{\circ} \mathrm{C}\right.$ for $\left.10 \mathrm{~min}\right)$ was followed by 10 touch-down cycles $\left(94^{\circ} \mathrm{C}\right.$ for $1 \mathrm{~min} ; 65^{\circ} \mathrm{C}-55^{\circ} \mathrm{C}$ for $1 \mathrm{~min}$ (a decrease of $1{ }^{\circ} \mathrm{C}$ after each cycle); $72^{\circ} \mathrm{C}$ for $1 \mathrm{~min} 30 \mathrm{~s}$ ) which was followed by another 10 touch-down cycles $\left(94^{\circ} \mathrm{C}\right.$ for $1 \mathrm{~min} ; 55^{\circ} \mathrm{C}-50^{\circ} \mathrm{C}$ for $1 \mathrm{~min}$ (a decrease of $0.5^{\circ} \mathrm{C}$ after each cycle); $72^{\circ} \mathrm{C}$ for $1 \mathrm{~min} 30 \mathrm{~s}$ ) and then 20 cycles $\left(94^{\circ} \mathrm{C}\right.$ for $45 \mathrm{~s} ; 50^{\circ} \mathrm{C}$ for $45 \mathrm{~s} ; 72^{\circ} \mathrm{C}$ for $\left.1 \mathrm{~min}\right)$, ending with a final elongation step $\left(72^{\circ} \mathrm{C}\right.$ for $\left.7 \mathrm{~min}\right)$ as adopted from Khan et al. (2013). The amplicons were visualized on $1 \%$ agarose gel, eluded and were sequenced. The sequences were analyzed and compared through Mutation Surveyor DNA variant analysis software version 3.97 (Soft Genetics) following the previously reported parameters (Khan et al. 2013).

\section{Gene expression analysis through Semi-quantitative PCR}

The cDNA was produced through Hyperscript ${ }^{\mathrm{TM}}$ First strand synthesis kit (GeneAll Biotechnology) by using 500 ng of RNA of each sample. The semi-quantitative PCR was done using $2 \mathrm{X}$ Topsimple DyeMIX_multi HOT master mix in thermal cycler (applied Biosystem v. 1). The primers used to semi-quantitative PCR are given in Table 1. The PCR product was visualized on $1 \%$ agarose gel and was quantified by ImageJ software. ACT2 gene was amplified by using the primers (ACT2-F: 5'CTGAGGTTCTATTCCAGCCATCC-3' and ACT2-R: 5'CCACCACTGAGGACAACATTACC -3') as housekeeping for the purpose of normalization.

\section{Statistical analysis}

The phenotypic and molecular data was statistically analyzed by performing analysis of variance (ANOVA) by using "agricolae package (Felipe 2009) in R core" (R Core Team 2019). The model used to test the significance of variation in phenotypic traits and DNA methylation levels: $Y i j=\mu T j+\varepsilon i j$ where $T$ represents treatment effect (well-watered vs drought stress conditions) and eij represents the residual effect. MS Excel was used for the calculation of standard deviation and graphical presentation of the data.

\section{Results}

\section{Drought stress decrease plant growth}

Plants showed significant decrease in fresh weight and $6^{\text {th }}$ leaf length whereas a significant increase in the primary root length was also observed under drought stress (DS) conditions (Fig. 1 and Table 2). The plants under drought stress showed clear signs of wilting and stunted growth of secondary roots as compared to the plants grown under normal conditions (Fig. 1).

\section{Overall DNA methylation pattern of promoter region of $Z m E X P B 2$ under well-watered conditions}

Under WW conditions, fragment $-1.7 \mathrm{k}$ showed $77 \%$ of CG sites ( 7 out of 9), $73 \%$ of CHG sites (11 out of 15 ) and $38 \%$ of $\mathrm{CHH}$ sites (20 out of 52) showed certain level of methylation. Fragment $-1.3 \mathrm{k}$ showed $100 \%$ of CG sites (13 out of 13), $90 \%$ of CHG sites (9 out of 10) and $21 \%$ of $\mathrm{CHH}$ sites (8 out of 37) showed certain level of methylation. Interestingly, fragment $-0.8 \mathrm{k}$ showed no methylation at any of the cytosine sites present in the fragment.

Overall, 65\% DNA methylation level at CG sites, 47\% DNA methylation level at CHG sites and 10\% DNA methylation level at CHH sites (Fig. 2) were observed in fragment $-1.7 \mathrm{k}$ under WW conditions. Fragment $-1.3 \mathrm{k}$ showed $98 \%$ DNA methylation level at CG sites, $72.5 \%$ at CHG sites and 7\% at $\mathrm{CHH}$ sites (Fig. 2). These results confirm that the DNA methylation of the promoter region of $Z m E X P B 2$ gene is heterogeneous along its sequence, i.e., regions $-1.7 \mathrm{k}$ and $-1.3 \mathrm{k}$ were methylated whereas the fragment $-0.8 \mathrm{k}$ was nonmethylated under $\mathrm{WW}$ conditions (Fig. 2). 
Table 1: Primer sequences and specification of PCR amplicons used for DNA methylation analysis

\begin{tabular}{|c|c|c|c|c|}
\hline Fragments & Primers & Sequence (5'-3') & $\begin{array}{l}\text { Position of fragments in the ZmEXPB2 gene from } 1800 \\
\text { bp upstream of TSS }\end{array}$ & Amplicon Size (bp) \\
\hline \multirow[t]{2}{*}{$-1.7 \mathrm{k}$} & $\mathrm{F}$ & ATATTTTTATTTAATTTGGAGGTT & $302-637$ & 338 \\
\hline & $\mathrm{R}$ & ATATTAAAACTTACTCTCСТАAACAA & & \\
\hline \multirow[t]{2}{*}{$-1.3 \mathrm{k}$} & $\mathrm{F}$ & TATTTTGTTTAGGAGAGTAAGTTTTAATA & $607-1031$ & 426 \\
\hline & $\mathrm{R}$ & AAAAACACAAATAATTTTTAAATCATA & & \\
\hline \multirow[t]{2}{*}{$-0.8 \mathrm{k}$} & $\mathrm{F}$ & GATTAAGGTGTTTTAAGATTTAAATAGA & $1281-1571$ & 291 \\
\hline & $\mathrm{R}$ & TAACTCACCTCACTAATCACTTATC & & \\
\hline \multirow[t]{2}{*}{$Z m E X P B 2-\mathrm{q}$} & $\mathrm{F}$ & CACCACCCACCACTACTACCA & $3997-4164$ & 163 \\
\hline & $\mathrm{R}$ & AACGACTCAAAGGACCATGACAA & & \\
\hline
\end{tabular}

Table 2: Effect of drought stress on phenotypic and molecular parameters of maize

\begin{tabular}{|c|c|c|c|}
\hline Parameters & & Well-watered & Drought stress \\
\hline \multirow[t]{3}{*}{ Phenotypic parameters } & $6^{\text {th }}$ Leaf length $(\mathrm{cm})$ & $35.63 \pm 4.22 \mathrm{a}$ & $23.20 \pm 1.59 \mathrm{~b}$ \\
\hline & Fresh biomass $\left(\mathrm{g}\right.$ plant $\left.^{-1}\right)$ & $11.01 \pm 1.92 \mathrm{a}$ & $6.30 \pm 1.17 \mathrm{~b}$ \\
\hline & Primary root length $(\mathrm{cm})$ & $28.67 \pm 2.08 b$ & $39.33 \pm 1.53 \mathrm{a}$ \\
\hline DNA methylation percentage of CG, & CG & $0.65 \pm 0.01^{\mathrm{NS}}$ & $0.71 \pm 0.007^{\mathrm{NS}}$ \\
\hline \multirow[t]{2}{*}{$\mathrm{CHG}$ and $\mathrm{CHH}$ in Fragment $-1.7 \mathrm{k}$} & CHG & $0.48 \pm 0.008^{\mathrm{NS}}$ & $0.51 \pm 0.0078^{\mathrm{NS}}$ \\
\hline & $\mathrm{CHH}$ & $0.10 \pm 0.001^{\mathrm{NS}}$ & $0.10 \pm 0.0051^{\mathrm{NS}}$ \\
\hline DNA methylation percentage of CG, & CG & $0.98 \pm 0.003 \mathrm{a}$ & $0.91 \pm 0.0032 \mathrm{~b}$ \\
\hline \multirow[t]{2}{*}{$\mathrm{CHG}$ and $\mathrm{CHH}$ in Fragment $-1.3 \mathrm{k}$} & CHG & $0.73 \pm 0.009 \mathrm{a}$ & $0.48 \pm 0.0019 b$ \\
\hline & $\mathrm{CHH}$ & $0.08 \pm 0.0005 b$ & $0.21 \pm 0.0005 \mathrm{a}$ \\
\hline Relative expression of ZmEXPB2 & & $0.88 \pm 0.106 \mathrm{~b}$ & $1.90 \pm 0.1414 \mathrm{a}$ \\
\hline
\end{tabular}

Means \pm standard deviation sharing same letters differ non-significantly $(P>0.05)$. NS represents non-significant results. The small alphabets represent the significant variation between well-watered and drought stressed plants at $P<0.05$

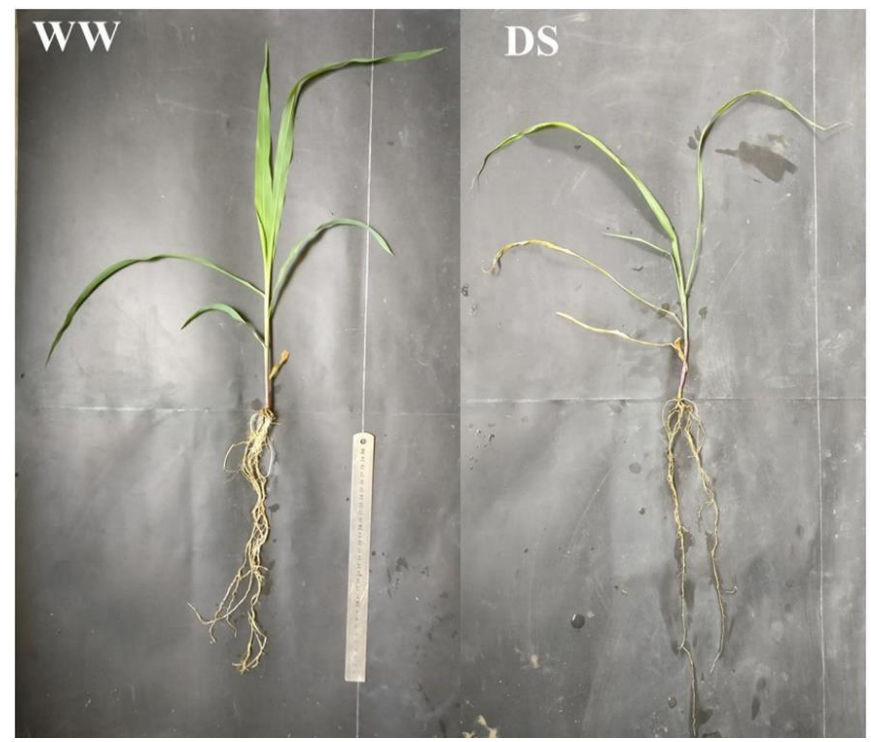

Fig. 1: Effect of drought stress on the phenotype of maize

WW and DS represent well-watered plants and drought stressed plant respectively

\section{Drought stress heterogeneously influences the DNA methylation pattern of the different regions in the promoter of $\mathrm{ZmEXPB2}$ gene}

Comparative analysis of WW and DS conditions revealed that all the three studied fragments showed their specific pattern. The fragment $-0.8 \mathrm{k}$ showed no DNA methylation in both normal and stress conditions. Fragments $-1.7 \mathrm{k}$ and $1.3 \mathrm{k}$ showed DNA methylation so, the results of each of these two fragments are separately elaborated.
In fragment $-1.7 \mathrm{k}$, no significant variation in overall DNA methylation profiles between WW and DS plants was observed in all three contexts (Table 2). Significant increase in DNA methylation percentage of only one out of $9 \mathrm{CG}$ sites, and only one out of 13 CHG sites was observed, when site per site analysis was performed (Fig. 3). Only 05 out of $52 \mathrm{CHH}$ sites showed significant shift (CHH54, CHH156 and $\mathrm{CHH} 282$ showed DNA hypomethylation whereas sites CHH181 and CHH282 showed DNA hypermethylation) in DNA methylation percentages due to stress conditions (Fig. 


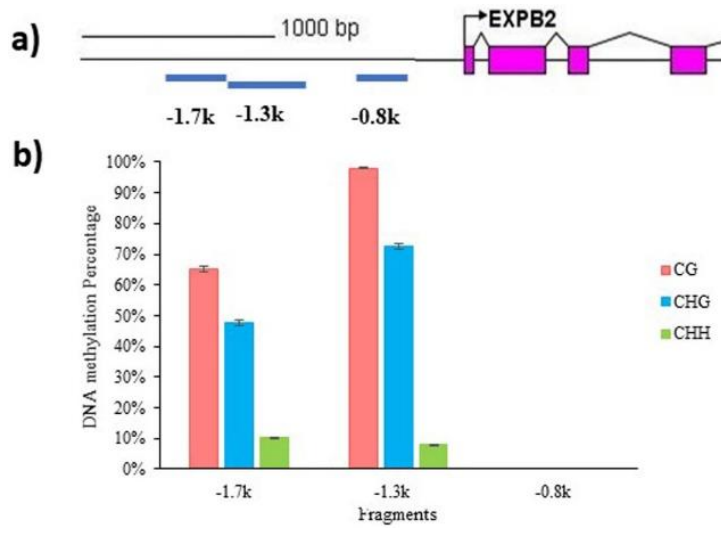

Fig. 2: DNA methylation pattern of studied regions of promoter of $Z m E X P B 2$ gene under normal conditions a) Gene structure of ZmEXPB2 gene (based on Genebank accession GRMZM2G021621) b) DNA methylation pattern of regions of promoter of ZmEXPB2 gene under well-watered conditions in three cytosine contexts Horizontal blue lines represent the studied regions in the promoter of ZmEXPB2

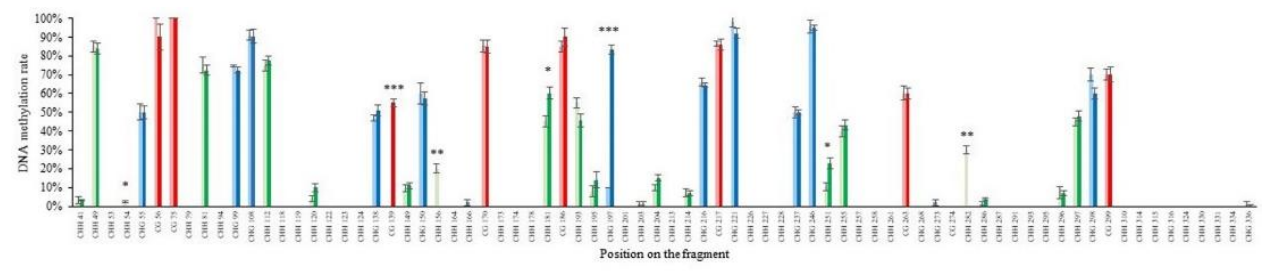

Fig. 3: Site per site DNA methylation variation in cytosine sites in $-1.7 \mathrm{k}$ region in promoter of ZmEXPB2 gene due to drought stress conditions. CG, CHG and CHH contexts, are represented in red, blue and green colors respectively

Faint and strong colors represent well-watered plants and drought stressed plants respectively. The numbers with the cytosine context shown in the $\mathrm{X}$-axis represent the position of that cytosine in the studied fragment. Statistical significance of methylation variation caused by drought is represented by stars with $* * P<0.01$ and $* * * P<0.001$

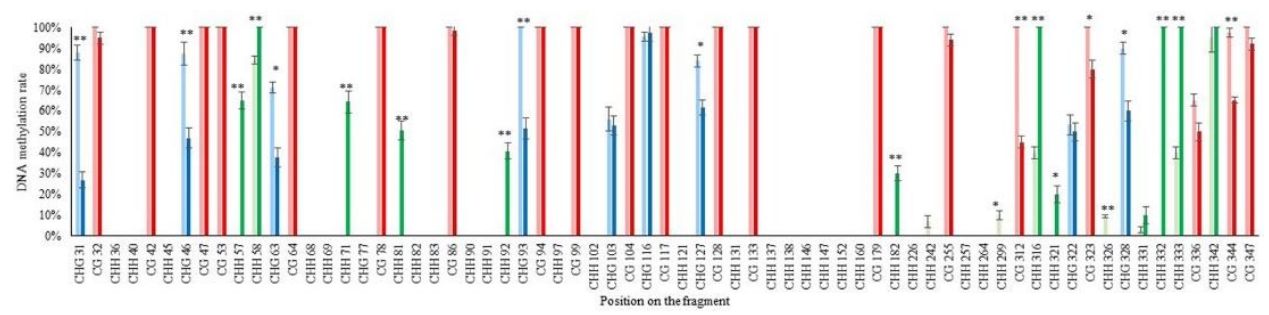

Fig. 4: Site per site DNA methylation variation in $-1.3 \mathrm{k}$ region in promoter of $\mathrm{ZmEXPB2}$ gene due to drought stress. $\mathrm{CG}, \mathrm{CHG}$ and $\mathrm{CHH}$ contexts, are represented in red, blue and green colors respectively

Faint and strong colors represent well-watered plants and drought stressed plants respectively. The numbers with the cytosine context shown in the X-axis represent the position of that cytosine in the studied fragment. Statistical significance of methylation variation caused by drought is represented by stars with $* * P<0.01$ and $* * * P<0.001$

3). These results confirm that DS does not affect overall DNA methylation profile at all the three contents $(\mathrm{CG}$, $\mathrm{CHG}, \mathrm{CHH}$ ) in this region.

In fragment $-1.3 \mathrm{k}$, the comparison of overall DNA methylation profile revealed significant shift under WD conditions in all the three contexts. DNA methylation percentage significantly decreased from $98 \%$ (in WW plants) to $90.9 \%$ (in DS plants) at CG sites, and from $72.5 \%$ (in WW plants) to $48.5 \%$ (in DS plants) at CHG sites. Interestingly, an inverse pattern of shift was observed in CHH sites where DNA methylation percentage showed significant increase from $7.8 \%$ (in WW plants) to $21.1 \%$ (in DS plants) (Table 2). The site per site analysis revealed that DNA methylation at many of the CG sites remained the same in WW and DS conditions. In contrast most of the
CHG sites (7 out of 9) showed significant decrease in DNA methylation due to DS conditions. Only a small fraction of CHH sites showed DNA methylation in WW and DS conditions. Interestingly, most of these $\mathrm{CHH}$ sites (10 out of 15) showed pattern of DNA hypermethylation due to drought stress conditions (Fig. 4). These results confirm that DS conditions significantly affect overall DNA methylation profile by inducing a shift in DNA methylation at all the three contents (CG, $\mathrm{CHG}, \mathrm{CHH})$ in this region and this shift is context specific.

\section{Drought stress condition causes increased gene expression of $\mathrm{ZmEXPB2}$}

Plants which experienced drought stress exhibited 
significantly higher level of $Z m E X P B 2$ gene expression as compared to plants grown in well-watered conditions (Table 2) confirming the upregulation of $Z m E X P B 2$ gene under DS conditions.

\section{Discussion}

The results of this study confirm the hypothesis that DNA methylation is involved in the regulation of a stress responsive gene, $Z m E X P B 2$, under drought stress conditions in maize and through this regulation, influence the plant stress response by playing its role in increasing the primary root length. Various studies have confirmed the involvement of epigenetic mechanisms like DNA methylation and histone modifications in the regulation of this gene under salt stress conditions (Li et al. 2014; Kaleem et al. 2019) but these studies particularly on DNA methylation provided very limited information as it used Methyl Sensitive Primers after bisulfite treatment which provides methylation status at only the cytosines present complimentary to primer sequence (Kaleem et al. 2019). Therefore, to further elaborate the involvement of DNA methylation in regulation of $Z m E X P 2$ gene in drought stress conditions, an in-depth analysis of DNA methylation in the promoter region of this gene was carried out.

DNA methylation was first analyzed under wellwatered conditions to identify the position for initiation and termination of DNA methylation across the promoter. The data suggests that DNA methylation appeared in the distant regions of promoter, increased in the middle region and then diminished in the closer part to TSS. These results indicates towards the varying role and level of involvement of these fragments in the regulation of the $Z m E X P B 2$ gene and also points out that the regulatory elements present in the middle or distal parts (from TSS) in the promoter may play critical role through their involvement in the epigenetic regulation of this gene. Previous reports in both plant and mammals confirm this observed pattern that different regions in the regulatory regions or in the body of the gene may show different DNA methylation patterns and may be critical for gene regulation (Feldmann et al. 2013; Gent et al. 2013; Khan et al. 2013).

The comparison between well-watered and drought stressed plants also revealed heterogeneity in the pattern of shift in DNA methylation profile of the three studied fragments, further strengthening the hypothesis that different region in the promoter of $Z m E X P B 2$ gene have their differential roles in gene regulation. The absence of any shift in DNA methylation pattern in fragment $-0.8 \mathrm{k}$ and $-1.7 \mathrm{k}$ show that DNA methylation is not involved in regulating the cis acting elements present in these fragments. Inversely, the fragment $-1.3 \mathrm{k}$ was identified which showed significant shift in the DNA methylation pattern under drought conditions indicating towards the involvement of DNA methylation in the regulation of the cis acting elements of this region. Similar pattern of heterogeneity in shift in DNA methylation pattern under varying environmental conditions have been shown in different studies like VRN1A gene in wheat where only regions in intron 1 showed shift in DNA methylation due to vernalization (Khan et al. 2013) and Asrl gene in tomato which also showed the varying pattern of DNA methylation shift due to drought stress in different regions along the gene (González et al. 2011).

In order to better understand the involvement of this fragment $(-1.3 \mathrm{k})$ in the gene regulation, in-depth DNA methylation analysis (site per site analysis) was performed. Interestingly, in fragment $-1.3 \mathrm{k}$, symmetric and asymmetric cytosine methylation showed inverse trends in the shift in DNA methylation. Under stress conditions, symmetric cytosine methylation (both $\mathrm{CG}$ and $\mathrm{CHG}$ sites) significantly decreased whereas asymmetric cytosine methylation significantly increased. Though the mechanism of de novo methylation is same for the three contexts, the maintenance of DNA methylation at these three contexts require different DNA methyltransferases, it appears that these contexts may have differential roles in gene regulation. The DNA methylation at asymmetric cytosine sites is maintained by RNA-directed DNA methylation (RdDM) depandent DOMAINS REARRANGED METHYLTRANSFERASE 2 (DRM2) and RdDM independent CHROMOMETHYLASE 2 (CMT2) (Zhang et al. 2018) whereas symmetric cytosine sites i.e., $\mathrm{CG}$ and $\mathrm{CHG}$ sites uses METHYLTRANSFERASE 1 (MET1) and CHROMOMETHYLASE 3 (CMT3) respectively for the maintenance (Lindroth et al. 2001; Law and Jacobsen 2010). Recently, differential pattern of shift depending upon the context of cytosine and their distinctive roles have been reported (Wang and Baulcombe 2020). DNA hypomethylation at symmetric cytosine methylation have inverse relationship with the gene expression (Song et al. 2012; Roessler et al. 2016). This decrease in DNA methylation of symmetric cytosine methylation is in accordance with the inverse relationship between promoter methylation and increased gene expression. Similar kind of DNA hypomethylation and increase in $Z m E X P B 2$ gene expression under salt stress conditions have been previously reported (Kaleem et al. 2019). The association between increased $\mathrm{CHH}$ in the upstream region of the promoter and increased gene expression has also been reported in maize (Gent et al. 2013). Therefore, it was anticipated that hypomethyation at symmetric cytosine site and hypermethylation at asymmetric cytosine sites in the middle region may induce an upregulation of $Z m E X P B 2$ gene. In consistence with these expectations, a significant increase in the ZmEXPB2 gene expression under drought stress conditions was observed in this study.

$E X P B 2$ belongs to expansins gene family which is one of the key regulators in cell wall elongation by modifying the cross-links between cellulose microfibrils and polysaccharides (Sharova 2007). It is an important gene that is involved in the regulation of root elongation in maize and 
in other species through controlling the cell wall extensibility (Kam et al. 2005; Guo et al. 2011). The significant upregulation of $Z m E X P B 2$ gene in the plant root under drought stress conditions indicates that it could be involved in the regulation of root length and may serve as an important candidate gene to be used in crop improvement prog. Our results of the phenotypic data confirm the correlation between the increase in gene expression of this gene and the observed increase in root length as a plant stress response which is in accordance with the previous reports (Kam et al. 2005; Guo et al. 2011). The drought stress conditions directly affect cell division and cell elongation due to deficit in external water potential (Farooq et al. 2009) therefore upregulation of this gene may have facilitated the cell elongation by regulating the cross-links between cellulose microfibrils and polysaccharides and induced an increase in the root length as an attempt by the plant to find more water and mitigate the stress conditions. From all these, it can be inferred that the observed increase in the primary root growth is a plant stress response against drought stress which is caused by an upregulation of ZmEXPB2 gene that is modulated by a differential shift in DNA methylation profile in the promoter region of ZmEXPB2 gene in maize.

\section{Conclusion}

Results of this pot experiment confirm the important role of DNA methylation in regulating the ZmEXPB2 gene under drought stress conditions. The middle region in the promoter of ZmEXPB2 gene was identified where symmetry dependent shift in DNA methylation across cytosine sites may cause an increase in the $Z m E X P B 2$ gene expression in the roots which in turn may induce the root growth under drought stressed conditions.

\section{Acknowledgements}

This paper is the part of MS thesis of Miss Zainab Rehman.

\section{Author Contributions}

$\mathrm{ZR}$ devised the methodology, conducted the investigation and helped in drafted the original manuscript. $A B$ and SMS curated and analyzed the data. GS, KA, MS and SR critically reviewed and edited the manuscript. ARK conceptualized and supervised the study, devised and validated the methodology, acquired funding, administered the project, provided resources and, drafted the manuscript.

\section{References}

Basir A, A Aziz, MA Khan, I Khan, M Adnan, S Fahad, AS Shah, IU Rehman, M Noor, A Rahman (2018). Phenology and growth traits response of maize (Zea mays L.) genotypes to semi-arid conditions. Pure Appl Biol 7:169-173

Bird A (2002). DNA methylation patterns and epigenetic memory. Genes Dev 16:6-21
Boron AK, BV Loock, D Suslov, MN Markakis, JP Verbelen, K Vissenberg (2015). Over-expression of AtEXLA2 alters etiolated Arabidopsis hypocotyl growth. Ann Bot 115:67-80

Conde D, A Moreno-Cortés, C Dervinis, JM Ramos-Sánchez, M Kirst, M Perales, P González-Melendi, I Allona (2017). Overexpression of DEMETER, a DNA demethylase, promotes early apical bud maturation in poplar. Plant Cell Environ 40:2806-2819

Danish S, M Zafar-ul-Hye, F Mohsin, M Hussain (2020). ACC-deaminase producing plant growth promoting rhizobacteria and biochar mitigate adverse effects of drought stress on maize growth. PLoS One 15; Article e 0230615

Egea I, I Albaladejo, V Meco, B Morales, A Sevilla, MC Bolarin, FB Flores (2018). The drought-tolerant Solanum pennellii regulates leaf water loss and induces genes involved in amino acid and ethylene/jasmonate metabolism under dehydration. Sci Rep 8; Article 2791

Ezquer I, I Salameh, L Colombo, P Kalaitzis (2020). Plant cell walls tackling climate change: Biotechnological strategies to improve crop adaptations and photosynthesis in response to global warming. Plants 9:212-237

Farooq M, N Gogoi, S Barthakur, B Baroowa, N Bharadwaj, SS Alghamdi, KHM Siddique (2017) Drought stress in grain legumes during reproduction and grain filling. J Agron Crop Sci 203:81-102

Farooq M, M Hussain, KHM Siddique (2014) Drought stress in wheat during flowering and grain-filling periods. Crit Rev Plant Sci 33:331-349

Farooq M, A Wahid N Kobayashi, D Fujita, SMA Basra (2009) Plant drought stress: Effects, mechanisms and management. Agron Sustain Dev 29:185-212

Feldmann A, R Ivanek, R Murr, D Gaidatzis, L Burger, D Schübeler (2013). Transcription factor occupancy can mediate active turnover of DNA methylation at regulatory regions. PLoS Genet 9; Article e1003994

Felipe DM (2009). A Statistical Analysis Tool for Agricultural Research. MS Thesis, National Engineering University (UNI), Lima, Peru

Gall HL, F Philippe, JM Domon, F Gillet, J Pelloux, C Rayon (2015). Cell Wall metabolism in response to abiotic stress. Plants 4:112-166

Geilfus CM, C Neuhaus, KH Mühling, C Zörb (2011). $\beta$-expansins are divergently abundant in maize cultivars that contrast in their degree of salt resistance. Plant Signal Behav 6:1279-1281

Gent JI, NA Ellis, L Guo, AE Harkess, Y Yao, X Zhang, RK Dawe (2013). CHH islands: De novo DNA methylation in near-gene chromatin regulation in maize. Genomic Res 23:628-637

Gheysari M, SH Sadeghi, HW Loescher, S Amiri, MJ Zareian, MM Majidi, P Asgarinia, JO Payero (2017). Comparison of deficit irrigation management strategies on root, plant growth and biomass productivity of silage maize. Agric Water Manage 182:126-138

González RM, MM Ricardi, ND Iusem (2013). Epigenetic marks in an adaptive water stress-responsive gene in tomato roots under normal and drought conditions. Epigenetics 8:864-872

González RM, MM Ricardi, ND Iusem (2011). Atypical epigenetic mark in an atypical location: Cytosine methylation at asymmetric (CNN) sites within the body of a non-repetitive tomato gene. BMC Plant Biol 11; Article 94

Guo W, J Zhao, X Li, L Qin, X Yan, H Liao (2011). A soybean $\beta$-expansin gene GmEXPB2 intrinsically involved in root system architecture responses to abiotic stresses. Plant J 66:541-552

Hussain M, A Latif, W Hassan, S Farooq, S Hussain, S Ahmad, A Nawaz (2019). Maize hybrids with well-developed root system perform better under deficit supplemental irrigation. Soil Environ 38:203-213

Hussain M, S Farooq, W Hasan, S Ul-Allah, M Tanveer, M Farooq, A Nawaz (2018). Drought stress in sunflower: Physiological effects and its management through breeding and agronomic alternatives. Agric Water Manage 201:152-167

Kaleem F, M Shahzad, G Shabir, K Aslam, SM Shah, AR Khan (2019). Salt stress induces genotype-specific DNA hypomethylation in ZmEXPB2 and ZmXET1 genes in maize. Cer Res Commun 47:216227

Kam MJ, HS Yun, PB Kaufman, SC Chang, SGK Kim (2005). Two expansins, EXP1 and EXPB2, are correlated with the growth and development of maize roots. J Plant Biol 48:304-310 
Kawanabe T, S Ishikura, N Miyaji, T Sasaki, LM Wu, E Itabashi, S Takada, M Shimizu, T Takasaki-Yasuda, K Osabe, WJ Peacock, ES Dennis, R Fujimoto (2016). Role of DNA methylation in hybrid vigor in Arabidopsis thaliana. Proc Natl Acad Sci USA 113:6704 6711

Khan AR, J Enjalbert, AC Marsollier, A Rousselet, I Goldringer, C Vitte (2013). Vernalization treatment induces site-specific DNA hypermethylation at the VERNALIZATION-A1 (VRN-A1) locus in hexaploid winter wheat. BMC Plant Biol 13; Article 209

Lang Z, M Lei, X Wang, K Tang, D Miki, H Zhang, SK Mangrauthia, W Liu, W Nie, G Ma, J Yan, CG Duan, CC Hsu, C Wang, WA Tao, Z Gong, JK Zhu (2015). The methyl-CpG-binding protein MBD7 facilitates active DNA demethylation to limit DNA hypermethylation and transcriptional gene silencing. Mol Cell 57:971-983

Lauss K, R Wardenaar, R Oka, MHAV Hulten, V Guryev, JJB Keurentjes, M Stam, F Johannes (2018). Parental DNA methylation states are associated with heterosis in epigenetic hybrids. Plant Physiol 176:1627-1645

Law JA, SE Jacobsen (2010). Establishing, maintaining and modifying DNA methylation patterns in plants and animals. Nat Rev Genet 11:204-220

Li F, S Xing, Q Guo, M Zhao, J Zhang, Q Gao, G Wang, W Wang (2011). Drought tolerance through over-expression of the expansin gene TaEXPB23 in transgenic tobacco. J Plant Physiol 168:960-966

Li H, S Yan, L Zhao, J Tan, Q Zhang, F Gao, P Wang, H Hou, L Li (2014). Histone acetylation associated up-regulation of the cell wall related genes is involved in salt stress induced maize root swelling. BMC Plant Biol 14; Article 105

Li Y, S Kumar, W Qian (2018). Active DNA demethylation: Mechanism and role in plant development. Plant Cell Rep 37:77-85

Lindroth AM, X Cao, JP Jackson, D Zilberman, CM McCallum, S Henikoff, SE Jacobsen (2001). Requirement of CHROMOMETHYLASE3 for maintenance of CpXpG methylation. Science 292:2077-2080

Liu R, A How-Kit, L Stammitti, E Teyssier, D Rolin, A Mortain-Bertrand, S Halle, M Liu, J Kong, C Wu, C Degraeve-Guibault, NH Chapman, M Maucourt, TC Hodgman, J Tost, M Bouzayen, Y Hong, GB Seymour, JJ Giovannoni, P Gallusci (2015). A DEMETER-like DNA demethylase governs tomato fruit ripening. Proc Natl Acad Sci USA 112:10804-10809

Lü P, M Kang, X Jiang, F Dai, J Gao, C Zhang (2013). RhEXPA4, a rose expansin gene, modulates leaf growth and confers drought and salt tolerance to Arabidopsis. Planta 237:1547-1559

Marowa P, A Ding, Y Kong (2016). Expansins: Roles in plant growth and potential applications in crop improvement. Plant Cell Rep 35:949965

Mi N, F Cai, Y Zhang, R Ji, S Zhang, Y Wang (2018). Differential responses of maize yield to drought at vegetative and reproductive stages. Plant Soil Environ 64:260-267

Murray MG, WF Thompson (1980). Rapid isolation of high molecular weight plant DNA. Nucl Acids Res 8:4321-4325
R Core Team (2019). R: A Language and Environment for Statistical Computing. R Foundation for Statistical Computing. Vienna, Austria. Available at https://www.R-project.org/

Roessler K, S Takuno, BS Gaut (2016). CG methylation covaries with differential gene expression between leaf and floral bud tissues of Brachypodium distachyon. PLoS One 11; Article e0150002

Shafiq S, NA Akram, M Ashraf (2019). Assessment of physio-biochemical indicators for drought tolerance in different cultivars of maize (Zea mays L.). Pak J Bot 51:1241-1247

Sharova EI (2007). Expansins: Proteins involved in cell wall softening during plant growth and morphogenesis. Russ J Plant Physiol 54:713-727

Song Y, D Ji, S Li, P Wang, Q Li, F Xiang (2012). The dynamic changes of DNA methylation and histone modifications of salt responsive transcription factor genes in soybean. PLoS One 7; Article e41274

Virlouvet L, MP Jacquemot, D Gerentes, H Corti, S Bouton, F Gilard, B Valot, J Trouverie, G Tcherkez, M Falque, C Damerval, P Rogowsky, P Perez, G Noctor, M Zivy, S Coursol (2011). The $Z m A S R 1$ protein influences branched-chain amino acid biosynthesis and maintains kernel yield in maize under water-limited conditions. Plant Physiol 157:917-936

Wang WS, YJ Pan, XQ Zhao, D Dwivedi, LH Zhu, J Ali, BY Fu, ZK Li (2011). Drought-induced site-specific DNA methylation and its association with drought tolerance in rice (Oryza sativa L.). $J$ Exp Bot 62:1951-1960

Wang Z, DC Baulcombe (2020). Transposon age and non-CG methylation. Nat Commun 11; Article 1221

Xing MQ, YJ Zhang, SR Zhou, WY. Hu, XT Wu, YJ Ye, XX Wu, YP Xiao, X Li, HW Xue (2015). Global analysis reveals the crucial roles of dna methylation during rice seed development. Plant Physiol 168:1417-1432

Zhang Y, CJ Harris, Q Liu, W Liu, I Ausin, Y Long, L Xiao, L Feng, X Chen, Y Xie, X Chen, L Zhan, S Feng, JJ Li, H Wang, J Zhai, SE Jacobsen (2018). Large-scale comparative epigenomics reveals hierarchical regulation of non-CG methylation in Arabidopsis. Proc Natl Acad Sci USA 115:1069-1074

Zhao M, Y Han, Y Feng, F Li, W Wang (2012). Expansins are involved in cell growth mediated by abscisic acid and indole-3-acetic acid under drought stress in wheat. Plant Cell Rep 31:671-685

Zhong S, Z Fei, YR Chen, Y Zheng, M Huang, J Vrebalov, R McQuinn, N Gapper, B Liu, J Xiang, Y Shao, JJ Giovannoni (2013). Single-base resolution methylomes of tomato fruit development reveal epigenome modifications associated with ripening. Nat Biotechnol 31:154-159

Zhou S, Y Han, Y Chen, X Kong, W Wang (2015). The involvement of expansins in response to water stress during leaf development in wheat. J Plant Physiol 183:64-74

Zilberman D, M Gehring, RK Tran, T Ballinger, S Henikoff (2007), Genome-wide analysis of Arabidopsis thaliana DNA methylation uncovers an interdependence between methylation and transcription. Nat Genet 39:61-69 